\title{
Nodal Spine Pairs Present in the Mimosoid Prosopis juliflora Are Not Stipules but Define a Distinct Class of Lateral Organs
}

\author{
Vishakha Sharma, Sushil Kumar* \\ National Institute of Plant Genome Research (NIPGR), New Delhi, India. \\ Email: "sushil2000_01@yahoo.co.in
}

Received May $16^{\text {th }}$, 2012; revised June $13^{\text {th }}$, 2012; accepted June $23^{\text {rd }}, 2012$

\begin{abstract}
The descriptions of Prosopis juliflora of subfamily mimosoideae in the family leguminosae, given in the floras of arid and semi-arid regions of the world, including the flora of Delhi, state that the spine pairs seen in association with compound leaf on nodes are stipules. The suggestions that spines are stipules were tested by morphological and histological examination of nodes of $P$. juliflora plants growing in the Arawalli range at New Delhi. The nascent nodes on growing branches of $P$. juliflora were observed to produce a pair of knife-like free bifacial stipules together with a leaf and a pair of spines. The stipules were missing from the mature nodes of the same branches whose young nodes carried stipule pairs, suggesting that the stipules were deciduous whereas leaves and spines were persistent. Anatomically, spines were observed to be appendages to stem and located adjacent to leaf petiole away from stipules. Vasculature of stipules was independent. The observations allowed the conclusion that $P$. juliflora nodes form regular stipules and spines produced on them are stem-like distinct lateral organs. It is suggested that nodal spine pairs borne on plant nodes in general are lateral organs different from stipules, leaves and secondary inflorescences.
\end{abstract}

Keywords: Lateral Organs; Leaf; Mimosoideae; Pisum sativum; Spines; Stipules

\section{Introduction}

Shoot architecture of angiospermic plants is largely dependent on the size, structure and relative arrangement of its vascularised lateral organs, formed on nodes of the main stem and branches [1]. Leaves and stipules in the vegetative phase and these and flower/fruit bearing secondary inflorescences in the reproductive phase are the principal lateral organs of most angiosperms [2]. Stipules are known to occur only in about a third of angiosperm species [3]. Usually formed in pairs, one on either side of the site of attachment of leaf to stem, stipules demonstrate enormous inter-species variation in size and structure [4]. Stipules are vestigial/inconspicuous in some species [4]. In other stipulate species, scaly, tendriller, spiny or foliaceous stipules of varying sizes and patterns have been treated as species specific taxonomic characters $[3,4]$. The genetic programmes of stipule differentiation have begun to be investigated [5-8]. In Pisum sativum, a model species for the study of stipule, leaf and flower/inflorescence development processes, the cochleata (coch), stipule reduced (st) and coch st mutants in the background of leaf mutants and 1-N-napthylpthalmic

\footnotetext{
*Corresponding author.
}

acid (NPA, an auxin transport inhibitor) treated $\mathrm{COCH}$ $S T$ shoots have been observed to produce nearly all of the reported patterns/morphologies of stipules, including tendriller stipules, except the scaly and spiny stipules [7-10]. These observations indicated parallel homoplasy $[10,11]$ in the network of genes involved in the determination of the large majority of angiosperm stipule types and sharing of genes between leaf and stipule differentiation $[9,10]$.

Spine (or thorn) pairs produced at nodes are reported as stipules in some species of very different families [2-4]. Nodal spine pairs are a characteristic of several species of the genera such as Acacia, Mimosa and Prosopis of the subfamily mimosoideae of the leguminoseae family [12-18]. Following two considerations led us to hypothesize that spines are lateral organs that are distinct from secondary inflorescences, leaves and stipules. 1) spines are radial structures, contrastingly different from most other types of stipules which are bifacial like leaves and leaflets [3,4]; 2) Spine-like stipules have not been observed among the genetic and induced stipule variants in $P$. sativum, a member of subfamily papilionoideae closely related to subfamily mimosoideae in the same family leguminosae [7-9]. The hypothesis was tested on 
Prosopis juliflora (Swartz) D.C. whose nodes are reported to carry spines as stipules. The nascently formed vegetative nodes and aged nodes were examined for their lateral organs morphologically and histologically. The study revealed that $P$. juliflora nodes bear small, free and bifacial deciduous stipules, and the spines are distinct lateral organs having origins of vasculature in stem, independent of that for stipules.

\section{Materials and Methods}

Areas of Aravalli range in and around the institute's campus were surveyed for adult plants of $P$. juliflora (Mimosoideae) and Eagle marmelos (Linnaeus) C. S. (Rutaceae) some of which were tagged for investigation. E. marmelos served as a control species in these experiments. Branches clipped from the identified trees were separated into nascent and mature nodes which were scanned using a Hewlett Packard PSC scanner and photographed using NIKON SMZ 1500 Stereozoom Microscope (Tokyo, Japan) and photographed with Nikon DXM 1200 cc digital camera. The nodes were fixed in formalin acetic alcohol and sectioned transversally with hand held rajor. Sections were stained with dilute safranine and observed microscopically with Nikon E100 microscope at $40 \times$ magnification. Microphotographs were taken by attaching microscope to Nikon 8400 digital camera.

\section{Results}

In accordance with the description given in floras, the adult nodes of $P$. juliflora and $E$. marmelos carried attached to stem a compound leaf and on each side of it a spine (Figures 1(a) and (d)). The young nodes of $E$. marmelos had the same composition of lateral organs as the mature nodes of E. marmelos. However, all the young nodes of $P$. juliflora carried, besides leaf and a pair of spines, a pair of free bifacial stipules of small size (Figure 1(b)). From side to side the arrangement of lateral organs on the young nodes of $P$. juliflora was visualized as stipule-spine-leaf-spine-stipule (Figure 1(a)). The sections at the nodes of the two species (Figures 1(c) and (f)) showed that the vasculatures of spines were located side by side as stem appendages. The vasculatures of the stipules in $P$. juliflora were on the periphery of those for leaf petiole (Figure 1(c)). In both P. juliflora and $E$. marmelos the the spine bases were seen behind the leaf petiole in the nascent nodes, however, in the mature nodes the spines occupied positions lateral to leaf petiole, apparently due to increase in the stem girth.

The stem sections at the nodes of P. juliflora and $E$. marmelos (Figures 1(c) and (f)) showed that spines were a part of stem. The outer tissues of stem continued uninterruptedly around the spines, although spines appeared

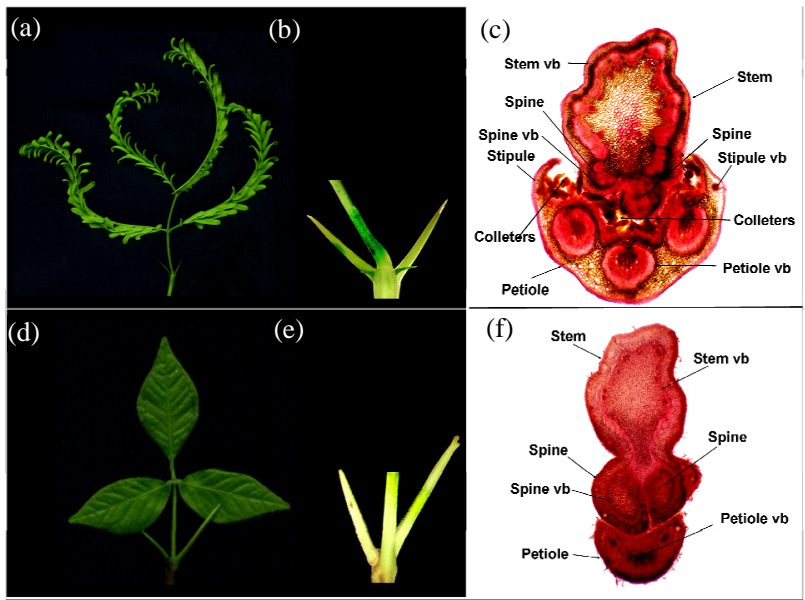

Figure 1. Composition of lateral organs at the vegetative nodes of Prosopis juliflora ((a), (b) and (c)) and Eagle marmelos ((d), (e) and (f)). (a) and (d), Lateral organs at a node: (a) = Bipinnate petiolated leaf, a pair of spines and a pair of stipules in $P$. juliflora; (d) = Trifoliate petiolated leaf and a pair of spines in Eagle marmelos. (b) and (e), Magnified view of node: $(b)=$ Stem node bearing a leaf petiole in the center, a pair of large spines and a pair of smaller stipules in $P$. juliflora; (e) = Stem node bearing a leaf petiole in the center and a spine is seen on each side on the back of petiole in E. marmelos. (c) and (f), Transverse sections of stem nodes: (c) = Colleters (epidermal glands) lie in between the stem and leaf petiole. Spines appear as stem appendages. Stipules have vascular bundles (vb) independent from the tripartite vasculature for leaf petiole. $(\mathrm{f})=$ Stem and leaf petiole are separate. Spines appear as stem appendages. The petiole has tripartite structure.

to have vascular bundle(s) well separated from the vasculature of the stem. The vasculature of petioles in both $P$. juliflora and E. marmelos (Figures 1(c) and (f)) was tripartite. The morphological absence of stipules in $E$. marmelos was in conformity with the absence of any extra vasculature in the petiole, unlike the petiole of $P$. juliflora in which distinct vascular bundles for the stipules could be visualized.

\section{Discussion}

In this study the lateral organs borne on the vegetative nodes of $P$. juliflora, a taxon of the subfamily mimosoideae of leguminosae family, and E. marmelos of the distant family Rutaceae were examined comparatively for some important morphological and histological features. E. marmelos nodes were observed to bear a leaf and a pair of spines. Whereas in this system, the vascular bundles of leaf had distinct origin from stem, those for spines appeared as stem appendages. The tissues of spines were anatomically (cell morphology-wise) similar in appearance to those in the stem. This indicated that spines of E. marmelos were stem-like radial lateral or- 
gans. In P. juliflora, the position of spines with respect to leaf petiole and stem on the nodes was similar to that in E. marmelos. The internal structure of spines of the two species was also similar. Therefore, it was concluded that spines are stem like lateral organs. The nodes of $P$. juliflora demonstrated the presence of vasculatures for stipules at the edges of petiole. Absence of extra vascularture at nodes in E. marmelos was in agreement with the absence of stipules.

The morphological and histological observations allowed the inference that stipules and spines were distict lateral organs in $P$. juliflora. Since stipules were absent from the mature nodes of $P$. juliflora due to their deciduous nature, while leaf and spines were persistent, it was concluded that stipules and leaf were also distinct lateral organs. Anatomical homology between the spines of very different/distant species $P$. juliflora and $E$. marmelos led to the suggestion that the radial nodal spine pairs, present in taxonomically different species, are independent stem-like lateral organs that are distinct from stipules which are usually bifacial.

It is thought that spines exemplify determinate stem growth. The gene network responsible for differentiation and growth of stem is expected to be shared by spines with modifications of some genetic regulatory events. Spines perhaps provide a novel model of organ development processes.

\section{Acknowledgements}

Grateful thanks are due to the Director of the institute for providing facilities and to Indian National Science Academy for scientist-ship to SK and SKA Institution for Research, Education and Development for post graduate fellowship to VS.

\section{REFERENCES}

[1] R. Sattler and R. Rutishauser, "The Fundamental Relevance of Morphology and Morphogenesis to Plant Research,” Annals of Botany, Vol. 80, No. 5, 1997, pp. 571582. doi:10.1006/anbo.1997.0474

[2] A. Cronquist, "The Evolution and Classification of Flowering Plants," The New York Botanical Garden Press, New York, 1988.

[3] A. A. Tyler, "The Nature and Origin of Stipules," Annals of the New York Academy of Science, Vol. 10, No. 1, 1897, pp. 1-49. doi:10.1111/j.1749-6632.1897.tb54954.x

[4] E. W. Sinnott and I. W. Bailey, "Investigations on the Phylogeny of Angiosperms. 3. Nodal Anatomy and the Morphology of Stipules," American Journal of Botany, Vol. 1, No. 9, 1914, pp. 441-453. doi:10.2307/2435043

[5] C. W. Gourlay, J. M. I. Hofer and T. H. N. Ellis, "Pea Compound Leaf Architecture Is Regulated by Interactions among the Genes UNIFOLIATA, COCHLETA, AFILA and TENDRIL-LESS,” Plant Cell, Vol. 12, No. 8, 2000, pp. 1279-1294.

[6] J. L. Yaxley, W. Jablonski and J. B. Reid, "Leaf and Flower Development in Pea (Pisum sativum L.): Mutants cochleata and unifoliata," Annals of Botany, Vol. 88, No. 2, 2001, pp. 225-234. doi:10.1006/anbo.2001.1448

[7] S. Kumar, R. K. Mishra, A. Kumar, S. Srivastava and S. Chaudhary, "Regulation of Stipule Development by COCHLEATA and STIPULE-REDUCED Genes in Pea (Pisum sativum)," Planta, Vol. 230, No. 3, 2009, pp. 449458. doi:10.1007/s00425-009-0952-0

[8] V. Sharma, A. K. Sinha, S. Chaudhary, A. Priyadarshini, B. N. Tripathi and S. Kumar, "Genetic Analysis of Structure and Function of Stipules in Pea Pisum sativum," Proceedings of Indian National Science Academy, Vol. 78, No. 1, 2012, pp. 9-34.

[9] V. Sharma, B. N. Tripathi and S. Kumar, "Organ-Wise Homologies of Stipule, Leaf and Inflorescence between Pisum sativum Genetic Variants, Delonix regia and Caesalpinia bonduc Indicate Parallel Evolution of Morphogenetic Regulation,” Plant Systematics and Evolution, Vol. 298, No. 6, 2012, pp. 1167-1175. doi:10.1007/s00606-012-0612-X

[10] A. Kumar, V. Sharma, M. Khan, B. N. Tripathi and S. Kumar, "Pisum sativum Wild-Type and Mutant Stipules and Those Induced by an Auxin Transport Inhibitor Demonstrate the Entire Diversity of Laminated Stipules Observed in Angiosperms," Protoplasma, 2012, (Published online). doi:10.1007/s00709-012-0397-3

[11] D. B. Wake, M. H. Wake and C. D. Specht, "Homoplasy: From Detecting Pattern to Determining Process and Mechanism of Evolution,” Science, Vol. 331, No. 6020, 2011, pp. 1032-1035. doi:10.1126/science. 1188545

[12] G. Lewis and B. Schrire, "Legumes of the World,” Royal Botanic Gardens, Kew, 2002.

[13] J. K. Maheshwari, “The Flora of Delhi,” Council of Scientific and Industrial Research, New Delhi, 1963.

[14] Anonymous, "Flora of Pakistan". http://www.efloras.org/florataxon.aspx?flora_id=5\&taxon _id=200012289

[15] Anonymous, "Entry for Prosopis Juliflora (Sw.) DC. [Family Leguminosae-Mimosoideae],” JSTOR Plant Science. http://plants.jstor.org/flora/flos001964

[16] J. Macfadyen, "The Flora of Jamaica; a Description of the Plants of That Island, Arranged According to the Natural Orders," Longman, Orme, Brown, Green and Longmans, London, Vol. 1, 1837, p. 351.

[17] Anonymous, "Handbook on Taxonomy of Prosopis in Mexico, Peru and Chile,” FAO Corporate Document Repository, 1983, p. 37.

[18] M. F. Wojciechouski, M. Lawin and M. J. Sanderson, “A Phylogeny of Legumes (Leguminosae) Based on Analysis of the Plastid matK Gene Resolve Many Well Supported Subclades with in the Family," American Journal of Botany, Vol. 91, No. 11, pp. 1846-1862. doi:10.3732/ajb.91.11.1846 